\title{
Histological and Electrical Properties of Rat Dorsal Root Ganglion Neurons Innervating the Lower Urinary Tract
}

\author{
Naoki Yoshimura, ${ }^{1,2}$ Satoshi Seki, ${ }^{2}$ Kristin A. Erickson, ${ }^{1}$ Vickie L. Erickson, ${ }^{1}$ Michael B. Chancellor, ${ }^{1}$ and \\ William C. de Groat ${ }^{2}$ \\ Departments of ${ }^{1}$ Urology and ${ }^{2}$ Pharmacology, University of Pittsburgh School of Medicine, Pittsburgh, Pennsylvania 15213
}

\begin{abstract}
We investigated whether primary afferent neurons innervating different regions of the lower urinary tract have different histochemical and electrophysiological properties. Neurons in rat L6 -S1 DRG were identified by axonal transport of a fluorescent dye. Neurofilamentnegative $\mathrm{C}$-fiber cells comprise $\sim 70 \%$ of bladder and proximal urethral afferent neurons that send axons through the pelvic nerves, but comprise a smaller proportion (51\%) of distal urethral neurons that send axons through the pudendal nerves. Isolectin-B4 (IB4) binding was detected in a higher percentage (49\%) of C-fiber neurons innervating the distal urethra than in those innervating the bladder or proximal urethra (18-22\%). Neurofilament-positive A-fiber neurons innervating the distal urethra had a larger average somal size than neurons innervating the bladder or proximal urethra. In patch-clamp recordings, the majority (70\%) of bladder and proximal urethral neurons were sensitive to capsaicin and exhibited TTX-resistant, high-threshold action potentials, whereas a smaller proportion (53\%) of distal urethral neurons exhibited TTX-resistant spikes. T-type $\mathrm{Ca}^{2+}$ currents were observed in $47 \%$ of distal urethral neurons with TTX-sensitive spikes, but not in TTX-sensitive bladder or proximal urethral neurons. In summary, afferent neurons innervating bladder or proximal urethra differ from those innervating distal urethra. The latter, which more closely resemble cutaneous afferent neurons, consist of a smaller number of C-fiber neurons containing a higher percentage of IB4-positive cells and a more diverse population of A-fiber neurons, some of which exhibit T-type $\mathrm{Ca}^{2+}$ channels. These differences may be related to different functions of respective target organs in the lower urinary tract.
\end{abstract}

Key words: neurofilament; capsaicin; dorsal root ganglion; urinary bladder; urethra; sphincter; isolectin-B4; TTX; $\mathrm{Ca}^{2+}$ current

\section{Introduction}

The afferent innervation of the lower urinary tract arises in the lumbosacral DRG and is carried in three sets of nerves: (1) pelvic and (2) hypogastric nerves, which innervate the urinary bladder and proximal urethra, and (3) the pudendal nerves, which innervate the mid-distal urethra and the external urethral sphincter (EUS). These afferent pathways consist of myelinated (A $\beta$-fiber and $\mathrm{A} \delta$-fiber) and unmyelinated (C-fiber) axons that exhibit a wide range of properties (Bradley et al., 1973; Perl, 1992). Some bladder C-fiber afferents in the pelvic nerves are mechanoinsensitive and only respond to chemical-nociceptive stimuli (Janig and Morrison, 1986; Habler et al., 1990; Dmitrieva and McMahon, 1996), whereas A $\delta$-fiber and some C-fiber bladder afferents that are mechanosensitive respond to slow bladder filling and provide information about bladder wall tension and/or bladder volume (Habler et al., 1993; Sengupta and Gebhart, 1994; Shea et al., 2000; Morrison et al., 2002). In contrast, myelinated urethral afferents in the pelvic and pudendal nerves are sensitive to urine flow (Talaat, 1937; Todd, 1964; Bahns et al., 1986) or contractions of the striated muscle of the urethral sphincter (de Groat et al., 2001). Thus, it seems likely that mechanosensitive afferent neurons innervating the bladder and distal urethra have

Received Dec. 4, 2002; revised Feb. 20, 2003; accepted Feb. 25, 2003.

This work was supported by National Institutes of Health Grants DK-49430, DK-57267, and P01-HD39768.

Correspondence should be addressed to Dr. Naoki Yoshimura, Department of Urology, University of Pittsburgh School of Medicine, Kaufmann Medical Building, Suite 700, 3471 Fifth Avenue, Pittsburgh, PA 15213. E-mail: nyos@pitt.edu.

Copyright $\odot 2003$ Society for Neuroscience $\quad$ 0270-6474/03/234355-07\$15.00/0 different properties. The mechanisms that might contribute to these differences were studied in the present experiments.

Information about the properties of afferent neurons innervating the lower urinary tract is important for understanding not only visceral nociception but also excretory mechanisms. Afferent input from the lower urinary tract to the lumbosacral spinal cord has an essential role in the initiation of urine storage and voiding reflexes (de Groat et al., 1981; Mallory et al., 1989). Low levels of afferent activity induced by bladder distension can trigger reflex contractions of the urethral outlet and promote continence, whereas high levels of activity can induce bladder contractions and voiding. Afferent input from the proximal urethra and EUS can also modulate bladder activity (Barrington 1931, 1941; Jung et al., 1999). Urethral-to-bladder reflexes activated by mechanical stimulation in the urethra can facilitate the micturition reflex and promote complete bladder emptying. However, contractions of striated muscles of the distal urethra can activate somatic afferents in the pudendal nerves that inhibit voiding (de Groat et al., 2001).

In the present study, we used patch-clamp and immunocytochemical techniques to investigate whether the electrophysiological, morphological, and chemical properties of afferent neurons innervating the distal urethra are different from those of the bladder and proximal urethra. A major focus of the study was to distinguish between neurons with myelinated and unmyelinated axons using neurofilament staining and the shape of the action potential (Lawson et al., 1993) and then to identify different types of C-fiber afferent neurons on the basis of the binding of isolectin-B4 (IB4), which identifies nonpeptidergic neurons 
Table 1. Histological properties of DRG neurons

\begin{tabular}{|c|c|c|c|}
\hline & Bladder ( $n=460$ cells) & Proximal urethra ( $n=364$ cells) & Distal urethra ( $n=320$ cells) \\
\hline NF-negative C-fiber neurons & 321 cells $(70 \%)(24.1 \pm 1.5 \mu \mathrm{m})$ & 247 cells $(68 \%)(24.5 \pm 1.4 \mu \mathrm{m})$ & 163 cells $\left(51 \%^{a}\right)(23.5 \pm 1.5 \mu \mathrm{m})$ \\
\hline IB4 $(+)$ & $58 / 321(18 \%)$ & $55 / 247(22 \%)$ & $80 / 163\left(49 \%{ }^{a}\right)$ \\
\hline IB4 (-) & $263 / 321(82 \%)$ & $192 / 247(78 \%)$ & $83 / 163\left(51 \%^{a}\right)$ \\
\hline NF-positive A-fiber neurons & 139 cells $(30 \%)(32.1 \pm 1.8 \mu \mathrm{m})$ & 117 cells $(32 \%)(33.3 \pm 1.8 \mu \mathrm{m})$ & 157 cells $\left(49 \%^{a}\right)(36.8 \pm 2.0 \mu \mathrm{m})^{b}$ \\
\hline IB4 (+) & $4 / 137(3 \%)$ & $6 / 117(5 \%)$ & $5 / 157(3 \%)$ \\
\hline IB4 (-) & 133/137 (97\%) & $111 / 117(95 \%)$ & $152 / 157(97 \%)$ \\
\hline
\end{tabular}

Data were obtained from four animals (six to seven DRG sections per each animal). NF, Neurofilament.

${ }^{a} p<0.05$ compared with the percentage of bladder or proximal urethral neurons ( $\chi^{2}$ test).

${ }^{b} p<0.05$ compared with the diameter of bladder or proximal urethral neurons ( $t$ test).

(Snider and McMahon, 1998). A preliminary report of these results has been published previously in abstract form (Yoshimura et al., 2001a).

\section{Materials and Methods}

Animal preparation. Experiments were performed on adult female Sprague Dawley rats (150-250 gm). Care and handling of animals were in accordance with institutional guidelines and were approved by the University of Pittsburgh Institutional Animal Care and Use Committee.

The subpopulations of DRG neurons, which innervate the urinary bladder, proximal urethra, or distal urethra, including the surrounding EUS, were labeled by retrograde axonal transport of a fluorescent dye, Fast Blue (FB; 4\% w/v; Polyloy, Gross Umstadt, Germany), which was injected into each organ according to procedures described previously for bladder injection (Yoshimura et al., 1994, 1998). To label neurons supplying the bladder, the bladder was exposed by a midline lower abdominal incision, and the dye was injected with a 29 gauge needle at four to six sites (total volume, 20-30 $\mu \mathrm{l}$ ) on the dorsal surface of the bladder under halothane anesthesia ( $n=12$ rats). In other animals $(n=11)$, to label neurons supplying the proximal urethra, dye was injected on both sides of the proximal urethral wall, starting $2 \mathrm{~mm}$ from the base of the bladder neck to the level of the pubic bone (total volume, 6-8 $\mu \mathrm{l}$ in four injections). To label neurons supplying the distal urethra, a part of the pubic symphysis was removed and then dye was injected bilaterally into the distal urethra (total volume, $6-8 \mu \mathrm{l}$ in four injections) at the site at which the EUS forms a ring of muscles surrounding the urethra under the pubic ramus ( $n=12$ rats). At each injection site, the needle was kept in place for 20-30 sec, and any leakage of dye was removed by application of a cotton swab. The injection site was then rinsed with saline, and the incision was closed.
Immunohistochemistry. Seven days after dye injection, animals were deeply anesthetized with pentobarbital $(80 \mathrm{mg} / \mathrm{kg}$, i.p.) and perfused through the left ventricle with $200 \mathrm{ml}$ of cold oxygenated Krebs-Ringer's solution, followed by a fixative consisting of $4 \%$ paraformaldehyde in 0.1 м PBS. After the perfusion, L6 and S1 DRGs were removed bilaterally and then postfixed for $4 \mathrm{hr}$ in the same fixative solution. The tissues were placed in PBS containing increasing concentrations of sucrose $(10,20$, and $30 \%)$ at $4^{\circ} \mathrm{C}$ for cryoprotection, frozen in mounting medium, and sectioned at $28 \mu \mathrm{m}$ on a cryostat. After mounting on gelatin-coated slides, the sections were washed and incubated with IB4 conjugated with FITC (10 $\mu \mathrm{g} / \mathrm{ml}$; Sigma, St. Louis, MO) for $24 \mathrm{hr}$. Sections were then washed and incubated with a monoclonal antibody to the $200 \mathrm{kDa}$ neurofilament polypeptide (clone RT97; Chemicon, Temecula, CA; dilutions, 1:2000) for $48 \mathrm{hr}$, followed by visualization with anti-mouse antibody conjugated to Cy3 applied at dilutions of 1:600 for $2 \mathrm{hr}$. The sections were coverslipped in glycerin solution.

Histological analysis. Sections were viewed under a fluorescent microscope (Olympus Optical, Tokyo, Japan). Each neuron was first checked for FB labeling with the UV filter to identify cells innervating respective FB-injected organs: bladder, proximal urethra, and distal urethra. Histological analyses of all FB-labeled neurons were performed on every third section to avoid duplicate analysis of cells. The somal size of FB-labeled afferent neuronal profiles, expressed as the average diameter calculated from the longest and shortest axes of the cells, was measured on all FB-labeled afferent neuronal profiles in which nuclei were identified. Cross-sectional areas for outlined cell profiles of FB-labeled neurons were also measured using Scion Image software (Scion Corp., Frederick, $\mathrm{MD})$. After completion of cell size measurements, the distribution of RT97 neurofilament immunoreactivity and FITC staining for IB4 binding in FB-labeled afferent neuronal profiles was analyzed under fluores-
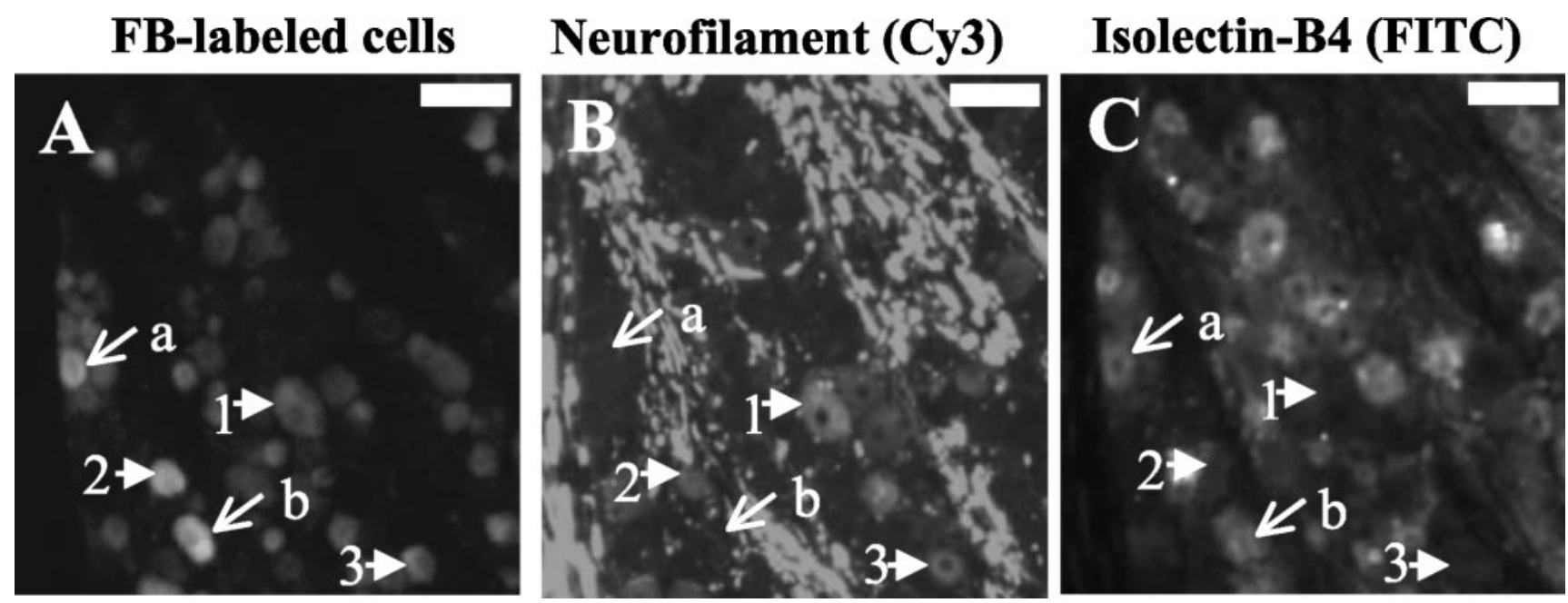

Figure 1. Photomicrographs of DRG sections showing neurofilament immunoreactivity and IB4 staining in FB-labeled neurons innervating the proximal urethra. $A$, Fluorescence photomicrograph for FB in a section of L6DRG. B, Fluorescence photomicrograph for Cy3 of the same DRG section as in $A$ showing neurofilament immunoreactivity C, Fluorescence photomicrograph showing FITC for IB4 staining in the same DRG section as in $A$. Arrows indicated by a and b show examples of neurofilament-negative $(B)$ and IB4-positive $(C)$ urethral afferent neurons labeled by FB $(A)$. Arrows indicated with 1-3 show the examples of neurofilament-positive $(B)$ and IB4-negative $(C)$ urethral afferent neurons labeled by $F B(A)$. Scale bar, $50 \mu \mathrm{m}$. 

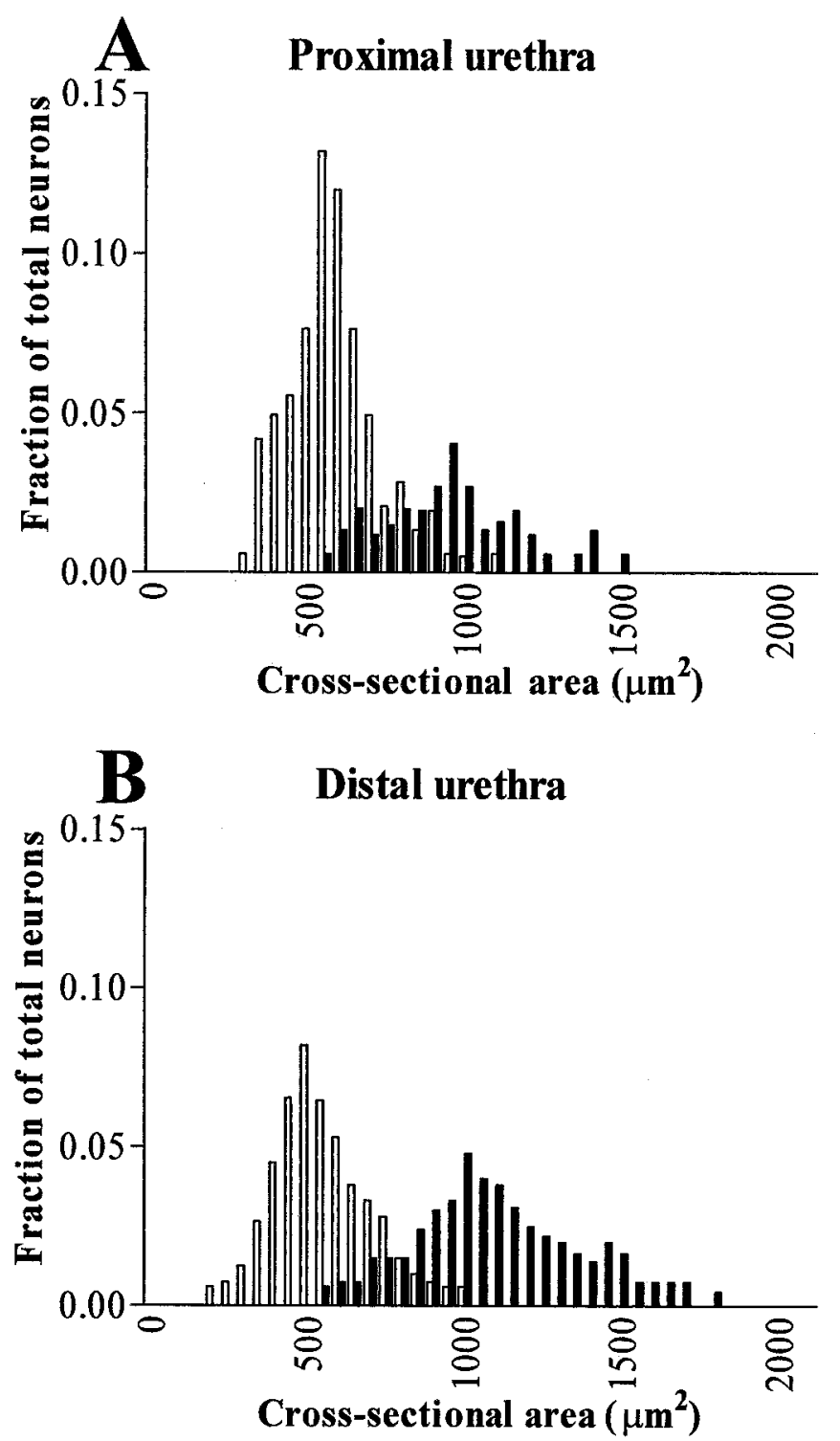

Figure 2. Histograms of cross-sectional somal areas of $L 6$ and S1 DRG cell profiles innervating the proximal urethra $(A)$ and distal urethra $(B)$. Abscissa indicate a size distribution (crosssectional somal area) with a bin width of $50 \mu \mathrm{m}^{2}$. Ordinate indicates the fraction of total cell population. Open and filled bars represent the fraction of neurofilament-negative and neurofilament-positive cell profiles, respectively.

cence illumination with the Cy3 filters and FITC filters, respectively. The intensity of RT97 neurofilament immunoreactivity and IB4 staining was rated on a four point scale, from completely negative (grade 0 ) to intense staining (grade 3 ). The neurons that exhibited grades 0 or 1 for RT97 immunoreactivity were considered to be neurofilament-negative C-fiber cells, whereas those with grades 2 or 3 were regarded as neurofilamentpositive A-fiber cells, as reported previously (Yoshimura et al., 1998). Similarly, the neuronal profiles that exhibited grades 0 or 1 for IB4 staining intensity were considered to be IB4-negative cells, whereas those with grades 2 or 3 were regarded as IB4-positive cells.

Cell preparation for patch-clamp recordings. Isolated neurons were dissociated from the DRG with enzymatic and mechanical methods, as described previously (Yoshimura et al., 1994, 1996). Briefly, L6 and S1 DRGs were dissected and incubated in a bath for $25 \mathrm{~min}$ at $35^{\circ} \mathrm{C}$ with $5 \mathrm{ml}$ of DMEM (Sigma) containing $0.3 \mathrm{mg} / \mathrm{ml}$ trypsin (type 3; Sigma), 1 $\mathrm{mg} / \mathrm{ml}$ collagenase (type 1; Sigma), and $0.1 \mathrm{mg} / \mathrm{ml}$ DNase (type 4; Sigma). Trypsin inhibitor (type 2a; Sigma) was then added to neutralize the activity of trypsin. Individual DRG cell bodies were isolated by trituration and then plated on poly-L-lysine-coated $35 \mathrm{~mm}$ Petri dishes. Dyelabeled primary afferent neurons that innervate the urinary bladder, proximal urethra, and distal urethra were identified using an inverted phase contrast microscope (Nikon, Tokyo, Japan) with fluorescent attachments (UV-1A filter; excitation wave length, $365 \mathrm{~nm}$ ). G $\Omega$-seal whole-cell recordings were performed at room temperature $\left(20-22^{\circ} \mathrm{C}\right)$ on each freshly dissociated, labeled neuron in a culture dish that usually contained two to five labeled cells among a few hundred unlabeled neurons. The internal solution used during current-clamp recordings of action potentials contained (in mM) $140 \mathrm{KCl}, 1 \mathrm{CaCl}_{2}, 2 \mathrm{MgCl}_{2}, 9 \mathrm{EGTA}$, 10 HEPES, $4 \mathrm{Mg}$-ATP, and $0.3 \mathrm{GTP}$ (Tris salt), adjusted to pH 7.4 with $\mathrm{KOH}(310 \mathrm{mOsm})$. Patch electrodes had resistances of 1-4 M $\Omega$ when filled with the internal solution. Neurons were superfused at a flow rate of $1.5 \mathrm{ml} / \mathrm{min}$ with an external solution containing (in $\mathrm{mM}$ ) $150 \mathrm{NaCl}$, $5 \mathrm{KCl}, 2.5 \mathrm{CaCl}_{2}, 1 \mathrm{MgCl}_{2}, 10 \mathrm{HEPES}$, and 10 D-glucose, adjusted to $\mathrm{pH}$ 7.4 with $\mathrm{NaOH}$ (340 mOsm). All recordings were made with an Axopatch-1D patch-clamp amplifier (Axon Instruments, Foster City, CA), and data were acquired and analyzed by pClamp software (Axon Instruments). Cell membrane capacitances were obtained by reading the value for whole-cell input capacitance neutralization directly from the amplifier. The duration of action potentials was measured at $50 \%$ of the spike amplitude. Thresholds for action potential activation were determined by injection of depolarizing current pulses in $10 \mathrm{pA}$ steps. In current-clamp recordings, data are presented from neurons that exhibited resting membrane potentials more negative than -40 $\mathrm{mV}$ and action potentials that overshot $0 \mathrm{mV}$.

After current-clamp recordings, $\mathrm{Ca}^{2+}$ channel currents conducted by $\mathrm{Ba}^{2+}$ ions were isolated by switching to an external solution containing (in $\mathrm{mm}$ ): $5 \mathrm{BaCl}_{2}, 155$ TEA-Cl, 5 4-aminopyridine, and 10 HEPES, adjusted to $\mathrm{pH} 7.4$ with TEA-OH (340 mOsm). Using this external solution, inward currents (mean peak amplitude, $3.1 \pm 0.3 \mathrm{nA} ; n=40$ cells) elicited by depolarizing pulses to $0 \mathrm{mV}$ from a holding potential of -90 $\mathrm{mV}$ were almost completely suppressed by $400 \mu \mathrm{M} \mathrm{CdCl}_{2}$ with a residual outward current of $21.6 \pm 3.9 \mathrm{pA}(n=11)$, indicating that contamination by $\mathrm{K}^{+}$currents was minimal under this condition (Yoshimura et al., 2001b). Cells in which excessive rundown was observed in a control period ranging up to $5 \mathrm{~min}$ were excluded from the experiments. In voltage-clamp recordings, the filter was set to $-3 \mathrm{~dB}$ at $2000 \mathrm{~Hz}$. Leak currents were subtracted by $\mathrm{P} / 4$ pulse protocol, and the series resistance was compensated by $60-80 \%$. All recordings were performed within 12 $\mathrm{hr}$ after dissociation.

TTX was applied to neurons by superfusion in the external solution. Capsaicin $(1 \mu \mathrm{M})$ was directly applied to the cells by pressure ejection (Picosplitzer; General Valve, Fairfield, NJ) through a glass pipette (10-20 $\mu \mathrm{m}$ tip diameter; $500 \mathrm{msec}$ at 5-10 psi). An inward shift of holding currents in voltage-clamp recordings was observed in capsaicin-sensitive cells. Capsaicin (Sigma) was dissolved in the normal external solution containing $10 \%$ alcohol and $10 \%$ Tween 80 at a concentration of $5 \mathrm{~mm}$ and then diluted in the external solution before experiments. No effects were detected by application of alcohol and Tween 80 in concentrations as high as $0.2 \%$.

All data are expressed as mean \pm SE. The data were analyzed by unpaired $t$ test or $\chi^{2}$ test. Welch's correction was made when equal variances of data were not demonstrated by the $F$ test. A level of $p<0.05$ was considered to be statistically significant.

\section{Results}

\section{Histological analyses of DRG sections}

The numbers of FB-labeled afferent neurons innervating the bladder, proximal urethra, and distal urethra, respectively, averaged $18.9 \pm 1.8,14.9 \pm 1.4$, and $12.1 \pm 1.2$ cell profiles per 28 - $\mu$ m-thick section $(n=4)$ in the L6 DRG and $5.4 \pm 0.4,4.3 \pm$ 0.4 , and $4.1 \pm 0.3$ cell profiles per section $(n=4)$ in S1 DRG. No FB-labeled cells were found in the L4 DRG, indicating that the tracer had not spread systemically to label afferent neurons non- 
specifically. We also confirmed that afferent neurons in L6-S1 DRG were predominantly labeled by dye transport through the pelvic nerve after bladder $(n=2)$ or proximal urethral $(n=2) \mathrm{FB}$ injection and through the pudendal nerve after FB injection to the distal urethra $(n=2)$, by transecting respective nerves after dye injection into the corresponding organs (data not shown).

The sizes of DRG neurons innervating the proximal urethra and the bladder were similar (Table 1). In bladder and proximal urethral afferent neurons, neurofilamentnegative cells (i.e., grades 0 and 1 staining for neurofilament immunoreactivity) were more numerous (70 and 68\%, respectively) and smaller in size than neurofilament-positive neurons (i.e., grades 2 and 3 staining), which comprised 30 and $32 \%$ of total neurons (Fig. 1, Table 1). However, in distal urethral afferent neurons, the numbers of neurofilamentpositive cells and neurofilament-negative cells were almost equal $(51 \%$ and $49 \%$,respectively). The average size of neurofilament-positive A-fiber neurons was significantly $(p<0.05)$ larger than the average size of neurofilament-positive Afiber neurons innervating the bladder or proximal urethra, whereas neurofilamentnegative C-fiber distal urethral neurons were similar in size to the bladder or proximal urethral C-fiber afferent neurons (Table 1). As shown in Figure 2, histograms of size distributions of proximal urethral and distal urethral afferent neurons clearly show a smaller number of neurofilament-negative C-fiber cells and broader size distribution of neurofilament-positive A-fiber cells among the distal urethral neuron population compared with the proximal urethral neuron population.

IB4-positive staining detected by FITC fluorescence was predominantly found in neurofilament-negative C-fiber afferent neurons in all three populations of neurons (Fig. 1, Table 1). However, the IB4-positive cells represented a significantly lower percentage of bladder (18\%) and proximal urethral neurofilament-negative C-fiber afferent neurons (22\%) than neurofilament-negative distal urethral afferent neurons (49\%) (Table 1).

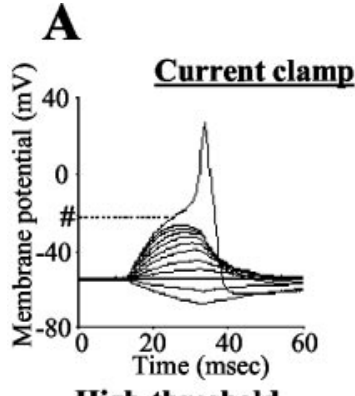
Long-duration spike

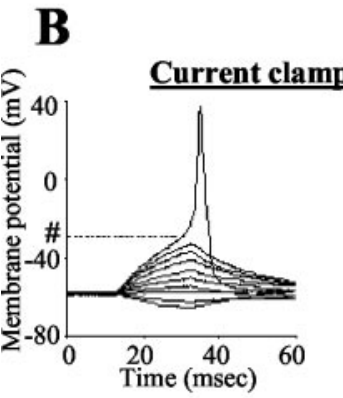

Low-threshold Short-duration spike
High-threshold

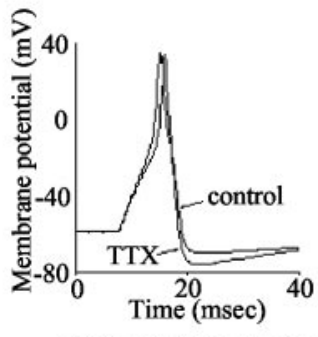

TTX-resistant spike

\section{Voltage clamp}

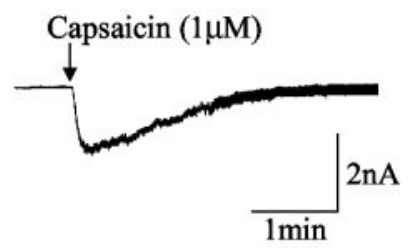

Sensitive to capsaicin
Figure 3. Characteristics of proximal urethral afferent neurons exhibiting TTX-resistant action potentials ( $24 \mu \mathrm{m}$ diameter; $A$ ) and TTX-sensitive action potentials ( $33 \mu \mathrm{m}$ diameter; $B$ ). The left panels are voltage responses and action potentials evoked by 30 msec depolarizing current pulses injected through the patch pipette under current-clamp conditions. A pound sign followed by a dotted line indicates the thresholds for spike activation $(-20 \mathrm{mV}$ in $A$ and $-29 \mathrm{mV}$ in $B)$. The middle panels show the effects of TTX application (1 $\mu \mathrm{M})$ on action potentials. The right panels show the responses to extracellular application of capsaicin (1 $\mu \mathrm{M})$ under voltage-clamp conditions. Note that the TTX-resistant urethral afferent neuron $(A)$ exhibited an inward current in response to capsaicin, whereas the TTX-sensitive afferent neuron showed no response to capsaicin.

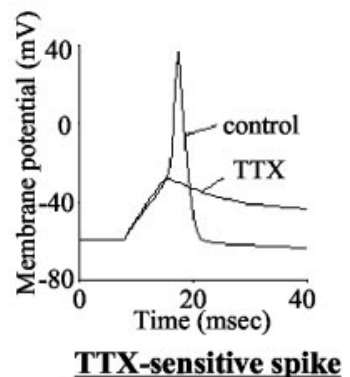

$\underline{\text { Voltage clamp }}$

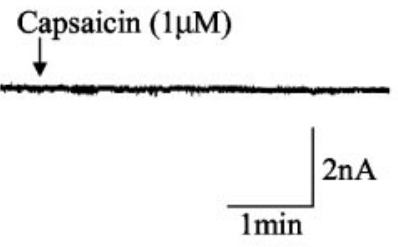

Insensitive to capsaicin

\section{TTX and capsaicin sensitivity of DRG neurons}

\section{Bladder neurons}

Approximately $71 \%$ of bladder afferent neurons exhibited longduration $(7.9 \pm 0.7 \mathrm{msec})$ action potentials that were resistant to TTX, whereas the remaining 17 bladder afferent neurons exhibited short-duration $(5.4 \pm 0.5 \mathrm{msec})$ action potentials that were reversibly blocked by $1 \mu \mathrm{M}$ TTX (Fig. 3, Table 2). The mean threshold of TTX-resistant spikes was $-20.4 \pm 1.1 \mathrm{mV}$, and the average size was $25.3 \pm 1.6 \mu \mathrm{m}$ in diameter. In bladder afferent neurons with TTX-resistant action potentials, 93\% of neurons exhibited inward currents in response to capsaicin application. Bladder afferent neurons that exhibited TTX-sensitive action potentials were significantly larger in size and had shorter-duration

Table 2. Electrical properties of DRG neurons

\begin{tabular}{llll}
\hline & Bladder $(n=59$ cells $)$ & Proximal urethra $(n=48$ cells $)$ & Distal urethra $(n=45$ cells $)$ \\
\hline TTX-resistant neurons & 42 cells $(71 \%)(25.3 \pm 1.6 \mu \mathrm{m})$ & 35 cells $(73 \%)(27.2 \pm 1.4 \mu \mathrm{m})$ & 24 cells $\left(53 \%^{a}\right)(26.2 \pm 1.3 \mu \mathrm{m})$ \\
$\quad$ Spike duration & $7.9 \pm 0.7 \mathrm{msec}$ & $8.1 \pm 1.1 \mathrm{msec}$ & $7.6 \pm 0.9 \mathrm{msec}$ \\
$\quad-20.4 \pm 1.1 \mathrm{mV}$ & $-22.4 \pm 2.1 \mathrm{mV}$ & $-21.6 \pm 1.6 \mathrm{mV}$ \\
$\quad$ Spike threshold & $28 / 30$ cells $(93 \%)$ & $20 / 22$ cells $(91 \%)$ & $16 / 17$ cells $(94 \%)$ \\
$\quad$ Capsaicin sensitivity & 17 cells $(29 \%)(33.1 \pm 2.1 \mu \mathrm{m})$ & 13 cells $(27 \%)(32.2 \pm 1.9 \mu \mathrm{m})$ & 21 cells $\left(47 \% \%^{a}\right)(37.8 \pm 1.9 \mu \mathrm{m})^{b}$ \\
TTX-sensitive neurons & $5.4 \pm 0.5 \mathrm{msec}$ & $4.9 \pm 0.8 \mathrm{msec}$ & $4.4 \pm 0.6 \mathrm{msec}$ \\
$\quad$ Spike duration & $-29.1 \pm 1.6 \mathrm{mV}$ & $-31.2 \pm 1.9 \mathrm{mV}$ & $-30.5 \pm 2.1 \mathrm{mV}$ \\
Spike threshold & $1 / 14$ cells $(7 \%)$ & $1 / 10$ cells $(10 \%)$ & $1 / 15$ cells $(7 \%)$ \\
Capsaicin sensitivity & & \\
\hline
\end{tabular}

Data were obtained from eight (bladder), seven (proximal urethra), and eight (distal urethra) rats.

${ }^{a} p<0.05$ compared with the percentage of bladder or proximal urethral neurons ( $\chi^{2}$ test).

${ }^{b} p<0.05$ compared with the diameter of bladder or proximal urethral neurons ( $t$ test). 

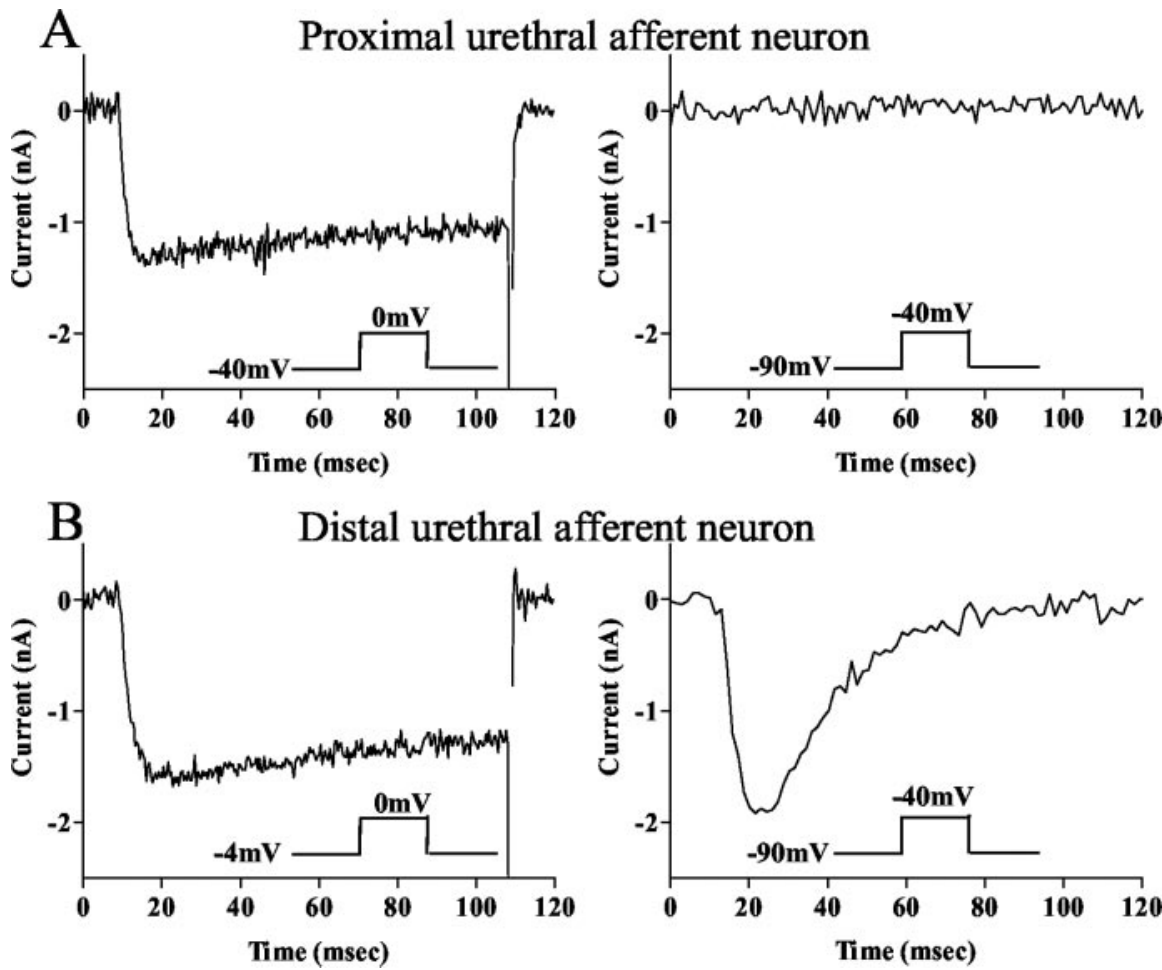

Figure 4. $\quad \mathrm{Ca}^{2+}$ channel currents in afferent neurons innervating the proximal urethra $(A)$ and distal urethra $(B)$ with TTXsensitive action potentials. $\mathrm{HVACa}^{2+}$ channel currents were induced by depolarizing pulses to $0 \mathrm{mV}$ from the holding potential of $-40 \mathrm{mV}$ (left panels). LVA, T-type $\mathrm{Ca}^{2+}$ channel currents were induced by depolarizing pulses to $-40 \mathrm{mV}$ from the hyperpolarized holding potential of $-90 \mathrm{mV}$ (right panels). Note that the fast-inactivating T-type $\mathrm{Ca}^{2+}$ channel current was found in the distal urethral neuron but not in the proximal urethral neuron.

$(5.4 \pm 0.5 \mathrm{msec})$ action potentials that were activated at significantly lower thresholds $(-29.1 \pm 1.6 \mathrm{mV})$ than TTX-resistant neurons. Only one of these neurons was sensitive to capsaicin.

\section{Proximal urethral neurons}

Proximal urethral afferent neurons could be divided into two populations according to the TTX $(1 \mu \mathrm{M})$ sensitivity of their action potentials. Approximately $73 \%$ of the neurons exhibited TTX-resistant long-duration $(8.1 \pm 1.1 \mathrm{msec})$ action potentials activated at high thresholds $(-22.4 \pm 2.1 \mathrm{mV})$ (Table 2$)$. The remaining 13 neurons had TTX-sensitive short-duration (4.9 \pm $0.8 \mathrm{msec})$ action potentials activated at low thresholds $(-31.2 \pm$ $1.9 \mathrm{mV})$. The somal size of the neurons with TTX-resistant spikes was significantly smaller than that of TTX-sensitive neurons (Table 2). Approximately $91 \%$ of neurons with TTX-resistant spikes were sensitive to capsaicin, whereas only 1 of 10 neurons with TTX-sensitive spikes was sensitive to capsaicin (Table 2). The size of TTX-resistant or TTX-sensitive proximal urethral neurons did not differ from those of bladder afferent neurons (Table 2).

\section{Distal urethral neurons}

Neurons with TTX-sensitive spikes comprised almost half (47\%) of the distal urethral afferent neuron population but a significantly smaller percentage $(27-29 \%)$ of bladder or proximal urethral afferent neurons (Table 2). Although the size of TTXresistant distal urethral neurons did not differ from those of TTXresistant proximal urethral neurons, the size of TTX-sensitive distal urethral neurons was significantly larger (by 17\%) than that of TTX-sensitive neurons innervating the proximal urethra. Neurons with TTX-resistant spikes were predominantly capsaicin sensitive (94\%), whereas only 1 of 15 neurons with TTXsensitive spikes was sensitive to capsaicin (Table 2).
$\mathrm{Ca}^{2+}$ channel currents

After examining action potential properties, $\mathrm{Ca}^{2+}$ channel currents carried by $\mathrm{Ba}^{2+}$ ions were evaluated in voltage-clamp recordings by switching to an external solution (described in Materials and Methods) that suppressed $\mathrm{Na}^{+}$and $\mathrm{K}^{+}$currents. Different command protocols were used to identify the expression of highvoltage-activated (HVA) and T-type, lowvoltage-activated (LVA) $\mathrm{Ca}^{2+}$ channel currents. Because it has been reported that T-type channels are almost completely inactivated at a holding potential of $-60 \mathrm{mV}$ and can be activated by membrane depolarization above $-50 \mathrm{mV}$ from hyperpolarized holding potentials (Carbone and Lux, 1987; Scroggs and Fox, 1992), we first examined $\mathrm{HVA} \mathrm{Ca}^{2+}$ channel currents induced by membrane depolarization to 0 $\mathrm{mV}$ from the holding potential at -40 $\mathrm{mV}$. HVA Ca ${ }^{2+}$ channel currents (range of peak current size, $0.8-2.8 \mathrm{nA}$ ), which were only slowly inactivated during 100 msec membrane depolarization, were found in both TTX-resistant and TTXsensitive populations of proximal urethral and distal urethral afferent neurons (Fig. 4). Thereafter, when the holding membrane potential was shifted to $-90 \mathrm{mV}$ and then depolarized to $-40 \mathrm{mV}$, approximately one-half of TTX-sensitive distal urethral afferent neurons (7 of 15 neurons, 47\%) exhibited T-type $\mathrm{Ca}^{2+}$ channel currents (range, 1.5-3.1 nA) that were almost completely inactivated during $120 \mathrm{msec}$ depolarizing pulses. However, T-type LVA Ca ${ }^{2+}$ channel currents exceeding $0.2 \mathrm{nA}$ were not detected in any TTX-resistant afferent neurons innervating the three organs tested ( $n=20,18$, and 21, respectively) or in TTX-sensitive neurons innervating the bladder $(n=$ 11) or proximal urethra $(n=12)$ (Fig. 4$)$.

\section{Discussion}

The results of the present study indicate that: (1) the properties of pelvic nerve afferent neurons innervating the proximal urethra are similar to those of bladder afferent neurons; (2) pudendal nerve afferent neurons innervating the distal urethra including the EUS consist of a smaller number of C-fiber neurons and a more diverse population of A-fiber neurons, some of which exhibit T-type $\mathrm{Ca}^{2+}$ channels; and (3) the proportion of IB4positive, presumed nonpeptidergic cells among $\mathrm{C}$-fiber afferent neurons is greater in the afferent population innervating the distal urethra than in those innervating the bladder and proximal urethra.

These differences in the afferent innervation of the proximal and distal parts of the lower urinary tract are consistent with the differences in the function of the two regions. The bladder and proximal urethra are composed of smooth muscles that exhibit slow distension and/or contraction (Morrison et al., 2002), whereas the distal urethra is composed in part of striated muscles that exhibit high-frequency rapid oscillations (bursting) during voiding (Maggi et al., 1986; de Groat et al., 2001). Smalldiameter, slow-conducting neural pathways and large-diameter, fast-conducting pathways with $\mathrm{T}$-type $\mathrm{Ca}^{2+}$ channels that are 
known to be involved in bursting-type activity (White et al., 1989; Huguenard, 1998) seem appropriate for the afferent innervation of these two regions of the lower urinary tract.

It has been reported that myelinated afferents innervating the urethra can contribute to bladder emptying during the voiding phase. Barrington $(1931,1941)$ has identified two components of this facilitatory urethra-to-bladder reflex. One component was activated by a somatic afferent pathway in the pudendal nerve and produced facilitation by a supraspinal mechanism involving the pontine micturition center (Barrington, 1931). The other component was activated by a visceral afferent pathway in the pelvic nerve and produced facilitation by a spinal reflex mechanism (Barrington, 1941). Talaat (1937) reported that during saline flow through the urethra in dogs, pudendal nerve afferents were activated at a much lower pressure compared with pelvic nerve afferent firing, which was induced by high-pressure flow that caused a distension of the urethra. High thresholds $(>60 \mathrm{~cm}$ of water) for activation of urethral afferents in the pelvic nerves were also identified recently in rats (Le Feber et al., 1998). It has also been documented that conduction velocities of cat pudendal nerve afferent fibers responding to electrical stimulation of the urethra are approximately twice as fast $(45 \mathrm{~m} / \mathrm{sec})$ as pelvic nerve afferent fibers responding to the same stimulation $(20 \mathrm{~m} / \mathrm{sec})$ (Bradley et al., 1973). In addition, it has been demonstrated that urethral afferents in the pudendal and pelvic nerves of the cat have different receptor properties. Pudendal nerve afferents responding to urine flow, some of which may be connected to Pacinian corpuscle-like structures in the muscle layers and the deeper parts of urethral mucosa, exhibited a slowly adapting firing pattern (Todd, 1964), whereas myelinated urethral afferents in the pelvic nerve are reportedly connected to rapidly adapting receptors (Bahns et al., 1986). Overall, the existence of lowthreshold, fast-conducting A-fibers in pudendal nerve afferents innervating the distal urethra is in accordance with the findings in the present study that myelinated pudendal nerve afferent neurons consist of more diverse populations of cells with larger somal size than myelinated A-fiber pelvic nerve afferents innervating the urethra. The existence of low-threshold, fast conducting A-fibers in pudendal nerve afferent pathways to the distal urethra is in accordance with the findings in the present study that distal urethral myelinated afferent neurons that travel in the pudendal nerve consist of a more diverse population of cells with larger somal size than myelinated A-fiber pelvic nerve afferents innervating the bladder and urethra. These results raise the possibility that the large-sized A-fiber population of distal urethral afferent neurons contains $A \alpha / \beta$-fiber cells, because myelinated $A \alpha / \beta$ fiber neurons are usually larger in size than $\mathrm{A} \delta$-fiber or $\mathrm{C}$-fiber cells (Lawson et al., 1993) that innervate the bladder (de Groat et al., 1981; Mallory et al., 1989).

Approximately one-half of TTX-sensitive A-fiber distal urethral afferent neurons exhibited transient, T-type $\mathrm{Ca}^{2+}$ channel currents that were not observed in TTX-sensitive A-fiber afferent neurons innervating the bladder and proximal urethra. These results are in line with previous findings that $\mathrm{T}$-type $\mathrm{Ca}^{2+}$ channel currents are expressed in a population of unidentified medium-sized A $\delta$-fiber DRG neurons that exhibited TTXsensitive sodium currents and capsaicin insensitivity (Cardenas et al., 1995, Villiere and McLachlan, 1996). Because it has been reported that T-type $\mathrm{Ca}^{2+}$ channel currents are involved in burst firing in thalamic and DRG neurons (White et al., 1989; Huguenard, 1998), it is tempting to speculate that A-fiber pudendal nerve afferent neurons exhibiting T-type $\mathrm{Ca}^{2+}$ channels may contribute to sustained firing patterns in pudendal nerve affer- ents that respond to urine flow (Todd, 1964) and to the bursting activity of striated urethral sphincter muscles during voiding (Maggi et al., 1986; de Groat et al., 2001).

Previous studies demonstrated that C-fiber afferent fibers identified by immunohistochemical staining for calcitonin generelated peptide or substance $\mathrm{P}$ were present in the subepithelium, the submucosa, and the muscular layer in all portions of the urethra (Hokfelt et al., 1978; Warburton and Santer, 1994). Moreover, the activation of these urethral C-fibers by capsaicin application elicited nociceptive behavioral responses, which disappeared after pudendal nerve transection (Lecci et al., 1994), as well as increased EMG activity of pelvic floor striated muscle, including the EUS (Conte et al., 1993; Thor and Muhlhauser, 1999). C-fiber afferents innervating the lower urinary tract seem to be subdivided into two populations on the basis of IB4 binding, as noted in the general population of DRG cells (i.e., IB4negative peptidergic and IB4-positive nonpeptidergic subpopulations) (Snider and McMahon, 1998). The present study showed that $49 \%$ of C-fiber distal urethral afferent neurons were IB4 positive, whereas only $18-22 \%$ of C-fiber bladder or proximal urethral afferent neurons were stained with IB4, indicating that pelvic nerve afferents innervating the proximal part of the lower urinary tract contain a larger population of peptidergic cells than pudendal nerve afferents innervating the distal urethra (Keast and de Groat, 1992). Somatic afferent neurons innervating the skin also have a larger percentage of IB4-positive cells than afferent neurons innervating the bladder (Bennett et al., 1996).

In conclusion, the present results suggest that there is a considerable variation in the properties of afferent neurons innervating different regions of the lower urinary tract. It seems likely that this heterogeneity is related to the different functions of the respective target organs.

\section{References}

Bahns E, Ernsberger U, Janig W, Nelke A (1986) Functional characteristics of lumbar visceral afferent fibres from the urinary bladder and the urethra in the cat. Pflügers Arch 407:510-518.

Barrington FJF (1931) The component reflexes of micturition in the cat. Parts I and II. Brain 54:177-188.

Barrington FJF (1941) The component reflexes of micturition in the cat. Part III. Brain 64:239-243.

Bennett DL, Dmietrieva N, Priestley JV, Clary D, McMahon SB (1996) trkA, CGRP and IB4 expression in retrogradely labelled cutaneous and visceral primary sensory neurones in the rat. Neurosci Lett 206:33-36.

Bradley W, Griffin D, Teague C, Timm G (1973) Sensory innervation of the mammalian urethra. Invest Urol 10:287-289.

Carbone E, Lux HD (1987) Kinetics and selectivity of a low-voltageactivated calcium current in chick and rat sensory neurones. J Physiol (Lond) 386:547-570.

Cardenas CG, Del Mar LP, Scroggs RS (1995) Variation in serotonergic inhibition of calcium channel currents in four types of rat sensory neurons differentiated by membrane properties. J Neurophysiol 74:1870-1879.

Conte B, Maggi CA, Giachetti A, Parlani M, Lopez G, Manzini S (1993) Intraurethral capsaicin produces reflex activation of the striated urethral sphincter in urethane-anesthetized male rats. J Urol 150:1271-1277.

de Groat WC, Nadelhaft I, Milne RJ, Booth AM, Morgan C, Thor K (1981) Organization of the sacral parasympathetic reflex pathways to the urinary bladder and large intestine. J Auton Nerv Sys 3:135-160.

de Groat WC, Fraser MO, Yoshiyama M, Smerin S, Tai C, Chancellor MB, Yoshimura N, Roppolo JR (2001) Neural control of the urethra. Scand J Urol Nephrol [Suppl] 207:35-43.

Dmitrieva N, McMahon SB (1996) Sensitisation of visceral afferents by nerve growth factor in the adult rat. Pain 66:87-97.

Habler HJ, Janig W, Koltzenburg M (1990) Activation of unmyelinated afferent fibres by mechanical stimuli and inflammation of the urinary bladder in the cat. J Physiol (Lond) 425:545-562.

Habler HJ, Janig W, Koltzenburg M (1993) Myelinated primary afferents of 
the sacral spinal cord responding to slow filling and distension of the cat urinary bladder. J Physiol (Lond) 463:449-460.

Hokfelt T, Schultzberg M, Elde R, Nilsson G, Terenius L, Said S, Goldstein M (1978) Peptide neurons in peripheral tissues including the urinary tract: immunohistochemical studies. Acta Pharmacol Toxicol 43 [Suppl 2]:79-89.

Huguenard JR (1998) Low-voltage-activated (T-type) calcium-channel genes identified. Trends Neurosci 21:451-452.

Janig W, Morrison JFB (1986) Functional properties of spinal visceral afferents supplying abdominal and pelvic organs, with special emphasis on visceral nociception. Prog Brain Res 67:87-114.

Jung SY, Fraser MO, Ozawa H, Yokoyama O, Yoshiyama M, de Groat WC, Chancellor MB (1999) Urethral afferent nerve activity affects the micturition reflex: implication for the relationship between stress incontinence and detrusor instability. J Urol 162:204-212.

Keast JR, de Groat WC (1992) Segmental distribution and peptide content of primary afferent neurons innervating the urogenital organs and colon of male rats. J Comp Neurol 319:615-623.

Lawson SN, Perry MJ, Prabhakar E, McCarthy PW (1993) Primary sensory neurones: neurofilament, neuropeptides, and conduction velocity. Brain Res Bull 30:239-243.

Lecci A, Giuliani S, Lazzeri M, Benaim G, Turini D, Maggi CA (1994) The behavioral response induced by intravesical instillation of capsaicin rats is mediated by pudendal urethral sensory fibers. Life Sci 55:429-436.

Le Feber J, van Asselt E, van Mastrigt R (1998) Neurophysiological modeling of voiding in rats: urethral nerve response to urethral pressure and flow. Am J Physiol 274:R1473-R1481.

Maggi CA, Giuliani S, Santicioli P, Meli A (1986) Analysis of factors involved in determining urinary bladder voiding cycle in urethananesthetized rats. Am J Physiol 251:R250-R257.

Mallory B, Steers WD, de Groat WC (1989) Electrophysiological study of micturition reflexes in rats. Am J Physiol 257:R410-R421.

Morrison JFB, Steers WD, Brading A, Blok B, Fry C, de Groat WC, Kakizaki H, Levin R, Thor K (2002) Neurophysiology and neuropharmacology. In: Second International Consultation on Incontinence, Chap 2 (Abrams P, Cardozo L, Khoury S, Wein A, eds) (sponsored by the World Health Organization), pp 83-163. Plymouth, UK: Plymbridge Distributors.

Perl ER (1992) Function of dorsal root ganglion neurons: an overview. In: Sensory neurons (Scott SA, ed), pp 3-23. New York: Oxford UP.

Scroggs RS, Fox AP (1992) Calcium current variation between acutely isolated adult rat dorsal root ganglion neurons of different size. J Physiol (Lond) 445:639-658.
Sengupta JN, Gebhart GF (1994) Mechanosensitive properties of pelvic nerve afferent fibers innervating the urinary bladder of the rat. J Neurophysiol 72:2420-2430.

Shea VK, Cai R, Crepps B, Mason JL, Perl ER (2000) Sensory fibers of the pelvic nerve innervating the rat's urinary bladder. J Neurophysiol 84:1924-1933.

Snider WD, McMahon SB (1998) Tackling pain at the source: new ideas about nociceptors. Neuron 20:629-632.

Talaat M (1937) Afferent impulses in the nerves supplying the urinary bladder. J Physiol (Lond) 89:1-13.

Thor KB, Muhlhauser MA (1999) Vesicoanal, urethroanal, and urethrovesical reflexes initiated by lower urinary tract irritation in the rat. Am J Physiol 277:R1002-R1012.

Todd JK (1964) Afferent impulses in the pudendal nerves of the cat. Q J Exp Physiol 49:258-267.

Villiere V, McLachlan EM (1996) Electrophysiological properties of neurons in intact rat dorsal root ganglia classified by conduction velocity and action potential duration. J Neurophysiol 76:1924-1941.

Warburton AL, Santer RM (1994) Sympathetic and sensory innervation of the urinary tract in young adult and aged rats: a semi-quantitative histochemical and immunohistochemical study. Histochem J 26:127-133.

White G, Lovinger DM, Weight FF (1989) Transient low-threshold $\mathrm{Ca}^{2+}$ current triggers burst firing through an afterdepolarizing potential in an adult mammalian neuron. Proc Natl Acad Sci USA 86:6802-6806.

Yoshimura N, White G, Weight FF, de Groat WC (1994) Patch-clamp recordings from subpopulations of autonomic and afferent neurons identified by axonal tracing techniques. J Auton Nerv Syst 49:85-92.

Yoshimura N, White G, Weight FF, de Groat WC (1996) Different types of $\mathrm{Na}^{+}$and $\mathrm{K}^{+}$currents in rat dorsal root ganglion neurones innervating the urinary bladder. J Physiol (Lond) 494:1-16.

Yoshimura N, Erdman SL, Snider MW, de Groat WC (1998) Effects of spinal cord injury on neurofilament immunoreactivity and capsaicin sensitivity in rat dorsal root ganglion neurons innervating the urinary bladder. Neuroscience 83:633-643.

Yoshimura N, Seki S, Erickson KA, Araki I, de Groat WC (2001a) Histochemical and electrical properties of dorsal root ganglion (DRG) neurons innervating rat urinary bladder, proximal urethra, and external urethral sphincter. Soc Neurosci Abstr 27:841.6.

Yoshimura N, Seki S, de Groat WC (2001b) Nitric oxide modulates $\mathrm{Ca}^{2+}$ channels in dorsal root ganglion neurons innervating rat urinary bladder. J Neurophysiol 86:304-311. 